\title{
ALTERNATIVE POWER TECHNOLOGIES: A DECISION MODEL FOR A SUGAR REFINERY
}

\author{
Stef Smith and Alessandra Orsoni \\ Kingston University, Faculty of Business and Law \\ Kingston Hill, Kingston upon Thames KT2 7LB, UK \\ E-mail: Stefanus.smith@peme.co.uk, a.orsoni@kingston.ac.uk
}

\section{KEYWORDS \\ Alternative Power Technologies, Decision Support, Multi-Criteria Decision Making, Fuzzy Logic.}

\begin{abstract}
This paper addresses the concerns of industrial users with regard to their dependence on the natural gas supply. Energy-intensive processes, such as sugar refining, are currently faced with important increases in their production costs due to the dramatic rise in the natural gas price over the past year. They are also faced with significant risks of supply cuts during possible gas balancing alerts. As many users are forced to re-evaluate their energy use and energy sources, this paper proposes a decision model to aid the systematic assessment of alternative power technologies for energy-intensive processes. The paper discusses the implementation and the use of the model referring to the case of a large EUbased sugar refinery.
\end{abstract}

\section{INTRODUCTION}

The dramatic increase in the price of natural gas and the vulnerability associated with possible supply cuts during a "gas balancing alert" has driven the need for large industrial users to consider alternative power sources and technologies.

Sugar refining is a highly energy intensive process approximately $2800 \mathrm{MJ}$ per ton of refined sugar. Due to the radical reform of EU sugar regime and changes in subsidies thereafter (ictsd.org), ensuring the long term sustainability of sugar refining facilities, requires substantial reductions in production costs. The reform cuts the guaranteed white sugar price by $39 \%$, forcing less competitive producers to leave the market. It is expected that $40 \%$ of the total EU sugar production will cease. Larger producers will also need to consider the long-term sustainability of their operations in the light of the higher gas price and assess the feasibility and the suitability of switching to alternative fuels.

The paper presents the case of Sugar \& Co. one of largest sugar refineries in the EU, where the name of the company has been modified due to standing confidentiality agreements. The refinery, operating in the sector since the 1880 s has a production capacity in excess of one million tons per year, which accounts for approximately $7 \%$ of the entire sugar production in the EU. Referring to the power requirements of Sugar \& Co., estimated as $15 \mathrm{MW}$, the paper will present a decision model for the systematic assessment and comparison of alternative power technologies.

While the model is customized and demonstrated referring to the case of Sugar \& Co., the decision process implemented in the model is generally applicable to any size of installation and type of industrial use. The model itself can easily be customised provided that a rationale for the rate of change in the unit costs with the size of the installed capacity is available for each alternative.

\section{POWER ISSUES IN SUGAR REFINING}

The sugar refining process lends itself to combined heat and power (CHP) generation. Natural gas combusts in boilers to produce high pressure steam, which is then used to drive steam turbines generating electricity. The steam pressure drops through the turbines to a level which is suitable for use in the refining process. Additionally, carbonation - a part of the sugar refining process - requires $\mathrm{CO}_{2}$ gas to react with calcium hydroxide. This reaction forms precipitate aiding the removal of impurities. The by-products of this process are water and calcium carbonate, which is used as a fertilizer. The $\mathrm{CO}_{2}$ is supplied to the carbonation process from the natural gas combustion in the CHP process.

Sugar \& Co. currently uses a combination of gas and steam turbines to power its production. The plant layout is shown in figure 1. The plant design and operation can accommodate a wide range of alternative energy sources. As indicated above, the sugar refining process requires steam, electricity and $\mathrm{CO}_{2}$ gas. The required quantities can be defined and the demand for these is unlikely to change unproportionally to production capacity. Specifically the plant layout permits three possible alternative strategies:

1) Alternative fuel for all or some of the boilers, on the condition that demand for $\mathrm{CO}_{2}$ gas is met

2) Alternative sources for electricity that can be used or the process and the excess sold to the grid.

3) Alternative methods to pre-heat water, thereby reducing the energy required to fuel the boilers. 


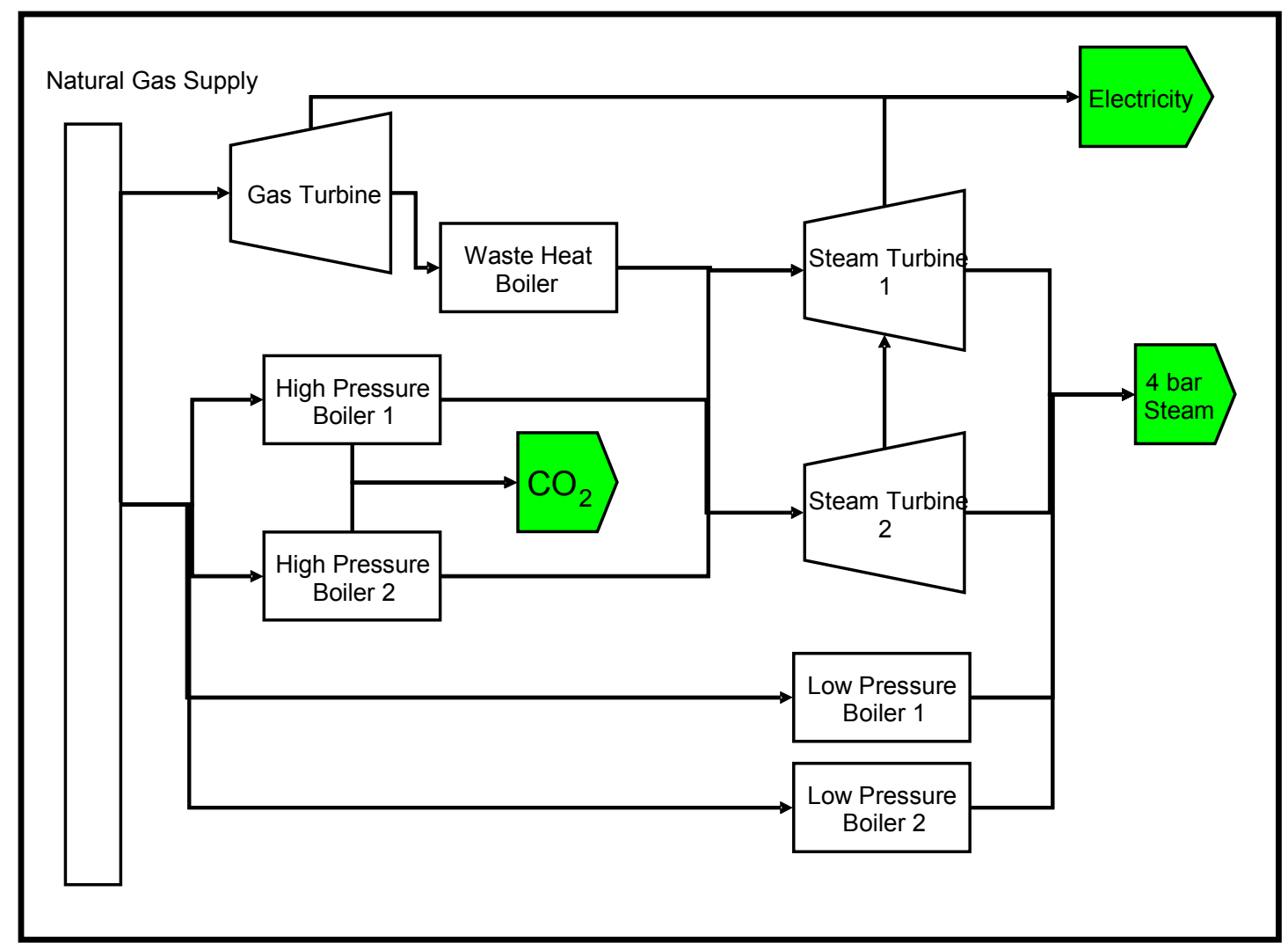

Figure 1: Sugar \& Co. Schematic of Plant Layout

The suitability of alternative energy sources cannot be determined through financial feasibility and suitability alone. The location and use of the land around the area are important in the decision making process, as some alternatives may not be aesthetically or environmentally suitable for use in the area. Historically part of the industrial sector, the site now forms part of and area which is now undergoing rapid reform. A large residential area separates the refinery and a major airport. Moreover the refinery produces a food ingredient hence some alternative fuel sources (such as waste) may not be perceived as fitting energy sources for a food producer. These issues will be considered when selecting the alternative energy sources to be considered in this study.

\section{DESIGN FEATURES OF THE DECISION MODEL}

Assessing alternative energy projects is a complex task and research in this area is still at the early development. The decision making methodology proposed by Kaminaris et al (2006) was developed to evaluate alternative technologies to replace or supplement existing supplies in a deregulated energy market where demand and supply are rapidly changing. The research was based on wind, solar and hydroelectric energy and did not involve alternatives to conventional combustible fuels like biomass technologies. Kaminaris et al (2006) suggested further research into this topic.
Kaminaris et al (2006) propose a fuzzy logic decision making methodology to handle the underlying uncertainties associated with new and rapidly developing technologies in a rapidly changing environment. Venetsanos et al (2002) argue that the assessment of renewable energy sources involves a number of uncertain factors including:

- Fossil fuel price

- Environmental regulations

- Energy demand

- Energy supply

- Capital cost and further technological development

- Market structure

Due to the relatively small capacity of energy generation at the refinery $(15 \mathrm{MW}$ total) versus the national demand for electricity, 340,403 GW in 2004 (Office for National Statistics), the influence of national electricity demand in this study is negligible. We further defined the supply characteristics (the plant demand) earlier and although process capability may change over the medium term, it stays well definable and involves only minor uncertainty. The market structure as described by Venetsanos et al. is the effect of electricity industry deregulation on the producer/consumer relationship. This topic applies to large industrial electricity suppliers and their customers and therefore 
also holds no relevance in this study. Environmental regulations in the UK are clear and although it may take time to apply for changes or concessions to environmental permits; it is assumed that this will not create uncertainty.

Although these factors should not create any uncertainties, there are others factors that may involve uncertainty and may influence the decision making in this study. These factors include:

- Fossil fuel price

- Fossil or bio-fuel sustainability

- Whole life cost (this does not only take into account the initial cost, but includes all costs from acquisition to disposal of the asset)

The world fossil fuel price is determined by supply and demand. Growth in energy demand is a function of economic growth. During 2004 the global economic output grew by $5 \%$, fuelled by a strong growth in the USA, Europe, Japan and China. Global demand and shortfalls in supply, mainly caused by a decline in OPEC spare capacity and disruptions in supply following the hurricanes in the Gulf of Mexico caused the fossil fuel price to reach record levels (Royal Dutch Shell, 2005). The complexity of the European gas supply network adds further price uncertainty.

For the same reason, although the long term sustainability of fossil fuels is guaranteed, the sustainability of the gas supply to industrial users is uncertain. The sustainability of other sources such as biofuel should also be the object of investigation.

The actual whole life cost, defined as the sum of all costs from acquisition to disposal including operational and maintenance expenses, of any alternative will at best be determined with severe uncertainty. A good example of the miscalculation of disposal costs are the extreme costs currently associated with asbestos removal, a substance historically used extensively for its good insulating properties. In this study it will be assumed that any such irregularities will be equal for each option and will therefore not affect the outcome of the decision process.

Further hidden uncertainties may exist. Unlike gas which is nationally supplied through an extensive piping network, the use of biomass fuels will require the development of a supply chain. If an alternative biomass fuel is considered, this fuel will need to be transported from source, probably by road, to the site. Because road transport utilise fossil fuels, the transportation cost carries the same uncertainty as the cost of gas.

To minimise the influence these uncertainties will have on the decision making process 4 strategies have been used. These are:

- The use of expert opinion and literature in the field
- The use of available data

- The sue of a combination of expert opinion and available data

- Sensitivity analysis on the uncertain variables, to determine the influence these variables have on the outcome of the decision making process

Approaches to deal with uncertainty in decision making have been developed. Goodwin et al. (2004) introduce the use of utility functions by attaching probability to consequences for different courses of action. This method requires a major time commitment from the decision maker and it lacks the transparency of the Simple Multi-attribute Rating Technique (SMART). When expert literature is used for data gathering, variables are often rated using linguistic information like almost or somewhat. Although the human brain is capable of dealing with linguistic information, it is impossible to deal with it in a probalistic way.

With the development of fuzzy logic Zadeh (1956, 1973, 1974, 1975, 1976) introduced the use of linguistic terms in decision making. The complexity and illdefinition of decision problems requires a linguistic approach, which is not a non-mathematical way of dealing with complex decisions, but a blend between the quantitative and qualitative (Zadeh, 1976). Fuzzy logic uses words in situations where numerical values are not suitable, as the meaning of word can be more precise. For these reasons fuzzy logic is now widely used in optimization and decision-making (Terano et al. 1992).

Because of its ability to handle uncertainty and linguistic variables, the use of fuzzy logic is well-suited for this study, but, it does hold another major advantage. Fuzzy logic can be used to map the characteristics of very diverse energy sources into the same set of performance measures, thereby making them comparable. To illustrate, the fuzzy variables defined by Kaminaris are discussed.

For the purposes of his study, where Kaminaris assessed the feasibility of developing an electricity production facility based on wind, solar or hydroelectric power, two fuzzy variables were defined. These variables are the life cycle analysis (LCA) of the system and the development cost (DC).

Similarly to the approach taken by Kaminaris, in this study two fuzzy variables are defined. The aim is to evaluate existing technologies in terms of suitability and feasibility versus the cost and risk of natural gas, thus it makes sense to define these variables as financial feasibility and risk. These two variables are sub-factored into relevant terms for each individual technology.

Financial feasibility is measured based on the Whole Life Cost of the project and future studies will also 
account for the total financial gain that can be realised from the use of the technology in the process. The site has limited space for a wind turbine or turbines or for the use of solar panels, therefore placing a restriction on the possible total financial gain. In the same way the use of a biomass to energy technology that does not produce the required level of $\mathrm{CO}_{2}$ gas will be restricted to only some of the boilers, again restricting its total financial gain. Because of the identified restrictions on the financial gains from each technology, which are site and process-dependant, these will not be included in the study for Sugar \& Co. but will be worth considering in other applications.

\section{MODEL IMPLEMENTATION AND USE}

The decisional model developed for this study aims at assessing the financial feasibility and the risk associated to the adoption of alternative energy sources against the natural gas as baseline solution.

The first step in the model implementation is the definition of the attributes for the financial feasibility and for the risk of a given technology. The key components of the financial feasibility are cost components relating to the life-cycle of the technology. These include the capital cost, the yearly cost of fuel, the yearly operation and maintenance costs, and possible decommissioning costs (when not covered by the scrap value of the equipment). The SMART approach requires to set weighing ctiteria for the attributes pertaining to a given objective (financial feasibility in this case). The weighing criteria used for this application aim at converting each cost component into its present value to ensure comparability. The life expectancy for each technology is taken into account, and the same opportunity cost of capital is assumed for all the technologies in the value of $7.5 \%$. The actual weights for the different cost components are the conversion factors used to report any future cost to its present value equivalent. Weighed costs are further normalized to enhance comparability. Suitable measures are defined to measure each cost component. The capital cost and the yearly costs of operation and maintenance are expressed as crisp values, while the yearly cost of fuel, expected to be uncertain, is expressed as a triangular fuzzy set. The cost of plant decommissioning is typically covered by the scrap velue of the equipment, and it would be difficult to estimate as a crisp value in other cases, therefore a linguistic scale ranging from "Lower" to "Higher" is defined to make comparative assessments between alternatives and the baseline solution. The natural gas supply, referred to as the baseline solution is assigned a reference value of "Similar", which in a normalized numerical scale (from 0 to 100) would translate into a reference value of 50 . In the same scale "Lower" translates as 0 and "Higher" translates as 100 . Intermediate values are also included: "Slightly Lower" mapping to 25 and "Slightly Higher" mapping to 75 .
The risk for each technology is the second objective of the decisional model, and it is intended as the risk of supply interruption. This is measured/described by a single attribute following the same linguistic scale proposed for the decommissioning cost.

For the case of Sugar \& Co. 4 alternative energy sources are considered. These are wind, biomass, solar, and marine technologies.

In order to enhance the systematic characterization and comparison among multiple alternatives, an object oriented solution based on Java ${ }^{\mathrm{TM}}$ classes is chosen. By these means not only can the assessment of the four alternatives be facilitated for the case of Sugar \& Co. but also the customization of the model for different power (capacity) requirements can be easily implemented alog with the representation of other technologies. The principles of the implemenatation follow the design specified in the following. A technology is represented at the high level as an abstract class, including the definition of all the high level attributes and general behaviour for the estimation of financial feasibility and risk, as defined above. Because of the specific features of each technology, the actual attributes and cost behaviour of each alternative are specified at the detailed level within a dedicated technology subclass. The actual instantiation and rating of each alternative for a specified capacity is delegated to a main application class, which also produces an output report with a feasibility rating and a risk rating for each alternative.

Table 1 and table 2 report the results calculated for Sugar 7 Co. referring to their current power requirement of $15 \mathrm{MW}$. Table 1 reports the actual cost figures and risk ratings, while Table 2 reports the present value (weighed and normalized) of each cost component together with the decision results for each alternative.

The decision results provided in table 2 indicate that a balanced trade-off between financial feasibility and risk of supply interruption is hard to achieve. On the one hand wind power is the least costly solution in terms of both installation and maintenance with zero fule costs, however it has the highest risk of supply interruption. On the other hand biomass is the most reliable solution as far as availability of supply, however it comes at the highest cost.

Marine power and possibly solar power are two balanced alternatives to natural gas. Marine power in particular is poverall less costly than natural gas with just a sligltly higer risk of supply interruption. Solar power is far more costly to install than any of the others including natural gas, however the availability of public incentives for the installation of solar power technology could dramatically cut this cost and make solar power the most effective alternative, given that marine power can only be accessed in coastal locations. 
Table 1: Cost Components: a Comparison among Alternatives for Sugar \& Co.

\begin{tabular}{|l|c|c|c|c|c|}
\hline Source & $\begin{array}{c}\text { Capital Cost } \\
{[\mathfrak{f}(\mathrm{k})]}\end{array}$ & $\begin{array}{c}\text { Fuel Cost } \\
{[\mathfrak{f}(\mathrm{k}) / \text { year }]}\end{array}$ & $\begin{array}{c}\text { Operation \& } \\
\text { Maint. Cost } \\
{[\mathfrak{f}(\mathrm{k}) / \text { year }]}\end{array}$ & $\begin{array}{c}\text { Decommiss. \& } \\
\text { Disposal Cost } \\
{[\text { verbal }]}\end{array}$ & $\begin{array}{c}\text { Risk of Supply } \\
\text { Interruption } \\
{[\text { verbal] }}\end{array}$ \\
\hline Biomass & $23,948.40$ & $1,103.76$ & 3375.00 & Similar & Slightly Lower \\
\hline Wind & $11,100.00$ & 0.00 & 360.00 & Lower & Higher \\
\hline Marine & $21,000.00$ & 0.00 & $2,235.00$ & Lower & Slightly Higher \\
\hline Solar & $64,605.00$ & 0.00 & $3,075.00$ & Lower & Slightly Higher \\
\hline Gas & $11,685.00$ & $2,010.42$ & 375.00 & Similar & Similar \\
\hline
\end{tabular}

Table 2: Normalised Values and Decision Results for Sugar \& Co.

\begin{tabular}{|l|c|c|c|c|c|c|}
\hline Source & $\begin{array}{c}\text { Normalised } \\
\text { Capital Cost } \\
\text { Rating }\end{array}$ & $\begin{array}{c}\text { Normalised } \\
\text { Fuel Cost } \\
\text { Rating }\end{array}$ & $\begin{array}{c}\text { Normalised } \\
\text { Operation } \\
\& \text { Maint. } \\
\text { Cost Rating }\end{array}$ & $\begin{array}{c}\text { Decommiss. } \\
\text { \& Disposal } \\
\text { Cost Rating }\end{array}$ & $\begin{array}{c}\text { Financial } \\
\text { Feasibi- } \\
\text { lity }\end{array}$ & $\begin{array}{c}\text { Risk of } \\
\text { Supply } \\
\text { Interrupt. }\end{array}$ \\
\hline Biomass & 37.07 & 54.90 & 100.00 & 50 & $\mathbf{1 9 1 . 9 7}$ & $\mathbf{2 5}$ \\
\hline Wind & 17.18 & 0.00 & 10.67 & 0 & $\mathbf{2 7 . 8 5}$ & $\mathbf{1 0 0}$ \\
\hline Marine & 32.51 & 0.00 & 66.22 & 0 & $\mathbf{9 8 . 7 3}$ & $\mathbf{7 5}$ \\
\hline Solar & 100.00 & 0.00 & 91.11 & 0 & $\mathbf{1 9 1 . 1 1}$ & $\mathbf{7 5}$ \\
\hline Gas & 16.63 & 100.00 & 11.11 & 50 & $\mathbf{1 2 7 . 7 4}$ & $\mathbf{5 0}$ \\
\hline
\end{tabular}




\section{CONCLUSION}

This research has developed a multicriteria decision support system for the assessment of alternative power sources and technologies against the natural gas supply. The implementation and use of the system has been demonstrated through a case study relevant to a large sugar refining facility, requiring an installed capacity of $15 \mathrm{MW}$. While the specific decision results are linked to the type of application and to the specified capacity requirements, the approach is highly generalisable and can easily be extended to accommodate different capacities and uses. The availability of accurate data on the variability of the unit costs with the size of the installed capacity will allow for sensitivity tests to assess the robustness of the solution within a range of the nominal $15 \mathrm{MW}$. Current research is looking for reliable correlations between the unit costs of the technology and the total installed capacity to asses whether a limited change in the size of the installation would change the recommended choice of technology.

\section{REFERENCES}

Goodwin, P. and G. Wright 2004. Decision Analysis for Management Judgement. Third Edition. England: John Wiley \& Sons Ltd..

Kaminaris, S.; Tsoutsos, T.; Agoris, D.; Machias, A. 2006. Assessing renewables-to-electricity systems: fuzzy expert system model. Energy policy No. 34, 1357-1366.

Office for National Statistics [WWW] Available from: www.statistics.gov.uk [Accessed: 03 September 2006].

Royal Dutch Petroleum Company 2005. Annual reports and accounts [WWW] Available from: www.shell.com [Accessed: 18 September 2006].

Terano, T.; Asai, K. and Sugeno, M. 1992. Fuzzy systems theory and it application. United Kingdom Edition. London, Academic press limited.

Venetsanos, K.; Angelopoulou, P. and Tsoutsos, T. 2002. Renewable energy sources project appraisal under uncertainty: the case of wind energy exploitation within a changing energy market environment. Energy policy No. 30/4, 293-307.

Zadeh, L. 1965. Fuzzy sets. Information and Control, No. 8/3, 338-353.

Zadeh, L. 1973. Outline of a new approach to the analysis of the complex systems and decision processes. IEEE Trans. on Systems, Man and Cybernetics, No.1/1, $28-44$.

Zadeh, L. 1974. Fuzzy logic and its application to approximate reasoning. Information processing, No. 74, 591-594

Zadeh, L.; Ho, Y. and Mitter, K. 1976. The linguistic approach and its application to decision analysis. Directions in large scale systems. Plenum press, New York, 339-370.

\section{AUTHOR BIOGRAPHIES}

STEF SMITH is currently completing his MBA at Kingston University (Kingston, UK) and he is working for PEME Process Control. He has previously received a B.Eng from the Potchefstroom University.

ALESSANDRA ORSONI is currently a senior lecturer in the School of Business Information Management at Kingston University (Kingston, UK). She received both her MS in Mechanical Engineering and her $\mathrm{ScD}$ in Engineering Systems Design and Innovation from the Massachusetts Institute of Technology (Cambridge, MA). Prior to joining Kingston University she was a research associate in the Department of Materials Science and Metallurgy at the University of Cambridge (Cambridge, UK) and worked as an assistant professor in the Department of Production Engineering at the University of Genova (Genova, Italy). Her research interests include modelling, simulation, and AI techniques applied to the design and management of complex industrial systems. 